\title{
Capnography: A Feasible Tool in Clinical and Experimental Settings
}

Capnography is the monitoring of the partial pressure of alveolar carbon dioxide $\left(\mathrm{CO}_{2}\right)$ in the respiratory gases. It is a useful noninvasive clinical tool for assessing efficiency and optimizing mechanical ventilation. ${ }^{1}$ The use of capnography for monitoring surgical patients during anesthesia and in the emergency department to confirm artificial airway placement is well-established and recommended. ${ }^{2}$ Capnography's importance as a standard of monitoring and patient safety in the ICU has been confirmed in recent years. ${ }^{1,3}$ Clinical uses of capnography in the ICU also include indirect assessment of cardiac output during weaning from cardiopulmonary bypass in patients without significant lung disease, monitoring of patients during changes in bed positioning, prognostic indicator of outcome in cardiac arrest, adjustment of the trigger sensitivity, and assessment of pulmonary circulation, recognizing the presence of pulmonary embolism as well as the effectiveness of chemical thrombolysis. ${ }^{4-8}$

Expiratory partial pressure of $\mathrm{CO}_{2}$ can be plotted against time (time-based capnography) or expired volume (volumetric capnography) on each breath. The capnogram is a graphical representation of the concentration or partial pressure of inhaled and exhaled $\mathrm{CO}_{2}$. Measurement of $\mathrm{P}_{\mathrm{aCO}_{2}}$ in arterial blood gas, although a true reflection of ventilatory efficiency, is far from ideal because of its invasive and intermittent nature. The main advantage of capnography over arterial blood gas is the ability to provide continuous $\mathrm{CO}_{2}$ monitoring, thus making trend assessments feasible. Although capnography does not replace arterial blood gas analysis $\left(\mathrm{P}_{\mathrm{aCO}}\right)$, it may decrease the required frequency.

Physiologically based indices derived from the capnographic waveform give direct information about ventilatory misdistributions and functional disturbances. Changes in the morphology of the capnogram indicate ventilation disturbances, and several indices based upon the geometry of the curve were developed in order to quantify ventilation homogeneity distribution.9-11 Moreover, capnography provides an assessment of ventilation/perfusion ratio (V/Q்) mis-

The authors have disclosed no conflicts of interest.

Correspondence: Pricila Mara Novais de Oliveira PhD, Rua Engenheiro José Carlos Moraes Sarmento, 332/401. Juiz de Fora, MG 36036-100, Brazil. E-mail: pricila.mno@gmail.com.

DOI: $10.4187 /$ respcare.04504 match through measurements of end-tidal $\mathrm{CO}_{2}\left(\mathrm{P}_{\mathrm{ETCO}_{2}}\right)$. The difference between $\mathrm{P}_{\mathrm{aCO}}$ and $\mathrm{P}_{\mathrm{ETCO}}$ in healthy subjects is very small, so $\mathrm{P}_{\mathrm{ETCO}_{2}}$ may reflect $\mathrm{P}_{\mathrm{aCO}}{ }^{.}{ }^{12}$ Many clinical situations could change $\mathrm{P}_{\mathrm{ETCO}_{2}}$ values, influencing the arterial-alveolar $\mathrm{CO}_{2}$ difference, which in healthy individuals is $<5 \mathrm{~mm} \mathrm{Hg} .{ }^{12}$ This difference can be significantly increased in the presence of lung diseases and some cyanotic heart diseases. Then, in an absence of $\dot{\mathrm{V} / \mathrm{Q}}$ mismatch, the $\mathrm{P}_{\mathrm{ETCO}_{2}}$ can be correlated to $\mathrm{P}_{\mathrm{aCO}}$.

\section{See the Original Study on Page 1548}

$\mathrm{P}_{\mathrm{ETCO}_{2}}$ is often used to optimize the ventilatory strategy and to assess potential changes in pulmonary blood flow. ${ }^{1}$ $\mathrm{P}_{\mathrm{ETCO}_{2}}$ measures the expired gas at the end of tidal volume; therefore, it is more representative of alveolar $\mathrm{CO}_{2}$ than airway gas. The $\mathrm{P}_{\mathrm{ETCO}_{2}}$ obtained from time-based capnography, when associated with arterial blood gas $\left(\mathrm{P}_{\mathrm{aCO}_{2}}\right)$, can be used to calculate the end-tidal alveolar dead-space fraction (end-tidal alveolar dead-space fraction $\left.=\left[\mathrm{P}_{\mathrm{aCO}_{2}}-\mathrm{P}_{\mathrm{ETCO}_{2}}\right] / \mathrm{P}_{\mathrm{aCO}_{2}}\right)$ utilized as an indicator of alveolar $\mathrm{V}_{\mathrm{D}}$. Hardman et al ${ }^{13}$ describe the end-tidal alveolar dead-space fraction as a reliable marker to quantify alveolar $\mathrm{V}_{\mathrm{D}}$. According to these authors, the end-tidal alveolar dead-space fraction is easy to obtain, useful, and safe at the bedside of ICU, infirmary, or emergency rooms when used correctly.

The time-based capnogram is the capnography method most commonly used in clinical practice. It provides only a quantitative measurement of $\mathrm{P}_{\mathrm{ETCO}_{2}}$, and it is not able to quantify directly alveolar $\mathrm{V}_{\mathrm{D}}$ or anatomic $\mathrm{V}_{\mathrm{D}}$. The volumetric capnogram, besides quantitative monitoring of the $\mathrm{P}_{\mathrm{ETCO}_{2}}$, provides extensive physiological information about production, transportation, and elimination of $\mathrm{CO}_{2}$ within the lungs through waveform patterns. ${ }^{9-11,14}$ Volumetric capnography, unlike time-based capnography, allows identification of $\mathrm{CO}_{2}$ from sequential emptying of alveoli, and anatomic $\mathrm{V}_{\mathrm{D}}$ measures, and evaluation of $\mathrm{V}_{\mathrm{D}}$ in each breath. Time-based capnography requires simpler equipment than does volumetric capnography, which involves a pneumotachometer attached to a capnograph, making it a more expensive apparatus. There are few volumetric capnographs commercially available, and most of them are attached to modern mechanical ventilators. 
Volumetric capnography is considered the best tool to measure dead-space volumes (physiological, alveolar, and anatomic), allowing a functional analysis and providing clinical clues about the efficiency of gas exchange. ${ }^{3}$ The $\mathrm{V}_{\mathrm{D}}$ increases when the alveolar-capillary interface is compromised (eg, COPD, atelectasis, and ARDS), ${ }^{15-17}$ during decreased pulmonary blood flow (eg, pulmonary embolism), ${ }^{18}$ or when alveoli are overdistended (eg, high PEEP). Physiological dead space $\left(\mathrm{V}_{\mathrm{D}}\right)$ involves the sum of anatomic $\mathrm{V}_{\mathrm{D}}$, consisting of the portion of the airways that conducts gas without gas exchange, and alveolar $\mathrm{V}_{\mathrm{D}}$, which consists of alveoli that are ventilated but not well perfused (V்/Q mismatch). The physiological $\mathrm{V}_{\mathrm{D}} / \mathrm{V}_{\mathrm{T}}$ ranges from 0.30 to 0.35 in healthy children. ${ }^{19}$ The $\mathrm{V}_{\mathrm{D}} / \mathrm{V}_{\mathrm{T}}>0.4$ can result in hypoxemia or hypercapnia due to $\dot{V} / \mathrm{Q}$ inequality.

Monitoring the $\mathrm{V}_{\mathrm{D}}$ and its ratio to tidal volume $\left(\mathrm{V}_{\mathrm{D}} / \mathrm{V}_{\mathrm{T}}\right)$ has proven to be valuable for monitoring patients on mechanical ventilation and for optimizing ventilatory strategies. $\mathrm{V}_{\mathrm{D}} / \mathrm{V}_{\mathrm{T}}$ has been studied as a measurement of extubation failure risk in children. ${ }^{20}$ Increased $V_{D}$ fractions also have been demonstrated to be strongly associated with an increased mortality in subjects with ARDS. ${ }^{21}$ AlmeidaJunior et al ${ }^{22}$ monitored $\mathrm{V}_{\mathrm{D}} / \mathrm{V}_{\mathrm{T}}$ in infants with acute bronchiolitis and reported an association between disease severity and $\mathrm{V}_{\mathrm{D}} / \mathrm{V}_{\mathrm{T}}$. Likewise, $\mathrm{V}_{\mathrm{D}} / \mathrm{V}_{\mathrm{T}}$ could be predictive of survival in ventilated newborn infants with congenital diaphragmatic hernia. ${ }^{23}$ Arnold et al ${ }^{23}$ claim that $\mathrm{V}_{\mathrm{D}} / \mathrm{V}_{\mathrm{T}}>$ 0.6 is associated with a 15 -fold increase in the rate of mortality.

$\mathrm{V}_{\mathrm{D}} / \mathrm{V}_{\mathrm{T}}$ reflects disturbances in the $\mathrm{V} / \mathrm{Q}$ ratio and is affected by any kind of $\dot{V} / \mathbf{Q}$ mismatch. Volumetric capnography is also used for monitoring the progression of lung diseases and evaluating the response of $\mathrm{V}_{\mathrm{D}} / \mathrm{V}_{\mathrm{T}}$ after changes in mechanical ventilation parameters, such as PEEP and $\mathrm{V}_{\mathrm{T}} \cdot{ }^{24,25}$ Furthermore, volumetric capnography can discriminate healthy individuals from those with lung disease, such as cystic fibrosis, bronchiectasis, COPD, lung fibrosis, and asthma, which presents a steeper slope of phase 3 of the capnogram. ${ }^{9-11}$

In this issue of Respiratory CARe, Bhalla et al ${ }^{26}$ correlated volumetric capnography versus time-based capnography measurements of $\mathrm{V}_{\mathrm{D}}$ and its fractions. Researchers calculated the $V_{D} / V_{T}$ and end-tidal alveolar dead-space fraction in 65 mechanically ventilated children and adolescents and found a higher correlation between the endtidal alveolar dead-space fraction and alveolar $\mathrm{V}_{\mathrm{D}} / \mathrm{V}_{\mathrm{T}}$ than with $\mathrm{V}_{\mathrm{D}} / \mathrm{V}_{\mathrm{T}}$. Monitoring changes in alveolar $\mathrm{V}_{\mathrm{D}}$ at the bedside in the ICU with time-based capnography could be simpler and easier than with volumetric capnography. According to Bhalla et al, ${ }^{26}$ the end-tidal alveolar dead-space fraction calculated by time-based capnography is as good as alveolar $\mathrm{V}_{\mathrm{D}} / \mathrm{V}_{\mathrm{T}}$ measured by volumetric capnography.

The interpretation of capnography must take into account the stability of physiologic variables, such as minute ventilation, $\mathrm{V}_{\mathrm{T}}$, cardiac output, and $\mathrm{CO}_{2}$ body storage. As a result, the evaluation and interpretation of capnographic data in children should be cautious, particularly in a critical care setting. Although the authors have described that data collection was made during a stable period, if capnography data had been recorded in a similar ventilation mode, bias could be reduced. Bhalla et al ${ }^{26}$ points out major factors that reduced the correlation between physiological and alveolar $\mathrm{V}_{\mathrm{D}} / \mathrm{V}_{\mathrm{T}}$ measured by volumetric capnography with time-based capnography (end-tidal alveolar dead-space fraction): high $\mathrm{V}_{\mathrm{D}} / \mathrm{V}_{\mathrm{T}}(>0.6)$, lower oxygenation $\left(\mathrm{P}_{\mathrm{aO}_{2}} / \mathrm{F}_{\mathrm{IO}_{2}}<200\right)$, a large anatomic $\mathrm{V}_{\mathrm{D}}(\geq 3 \mathrm{~mL} / \mathrm{kg})$, and the administration of inotropes or vasopressors. Those results are probably due to a higher $\dot{V} / \mathbf{Q}$ mismatch caused by an increase in anatomic $\mathrm{V}_{\mathrm{D}}$ in subjects with worse lung disease severity.

To summarize, capnography is promising and feasible in the ICU, emergency room, and anesthesia care unit for monitoring the lungs' ventilation/perfusion in mechanically ventilated patients. Volumetric capnography is the best capnography method to guide ventilatory support according to $\mathrm{V}_{\mathrm{D}}$ fractions, but it requires specialized and expensive equipment. As evidenced by Bhalla et al, ${ }^{26}$ timebased capnography may be a feasible and less expensive option to assess alveolar $\mathrm{V}_{\mathrm{D}}$ during mechanical ventilation in the ICU and reduce it, allowing a better $\dot{V} / \mathrm{Q}$ match. Despite its potential, capnography remains rarely used because health professionals are unaware of its usefulness in the bedside routine. As stated by Suarez-Sipmann et al, ${ }^{3}$ the time has come to take capnography out of the experimental setting and introduce it to guide ventilatory strategies in clinical practice.

\section{Pricila Mara Novais de Oliveira PhD}

Maternity Hospital Therezinha de Jesus, Faculty of Medical and Health Sciences (SUPREMA) Juiz de Fora, MG, Brazil

Marcos Mello Moreira PhD

Discipline of Pneumology, Department of Internal Medicine and, Participant Professor of Post-Graduated Program in Sciences of Surgery, Faculty of Medical School University of Campinas (UNICAMP) Campinas, SP, Brazil

\section{REFERENCES}

1. Walsh BK, Crotwell DN, Restrepo RD. Capnography/Capnometry during mechanical ventilation: 2011. Respir Care 2011;56(4):503509.

2. Neumar RW, Otto CW, Link MS, Kronick SL, Shuster M, Callaway CW, et al. 2010 American Heart Association Guidelines for Cardiopulmonary Resuscitation and Emergency Cardiovascular Care. Part 


\section{Capnography in Clinical and Experimental Settings}

8.1: Adjuncts for Airway Control and Ventilation. Circulation 2010; 122(18 Suppl 3):S729-S767.

3. Suarez-Sipmann F, Bohm SH, Tusman G. Volumetric capnography: the time has come. Curr Opin Crit Care 2014;20(3):333-339.

4. Maslow A, Stearns G, Bert A, Feng W, Price D, Schwartz C, et al. Monitoring end-tidal carbon dioxide during weaning from cardiopulmonary bypass in patients without significant lung disease. Anesth Analg 2001;92(2):306-313.

5. Ahrens T, Schallom L, Bettorf K, Ellner S, et al. End-tidal carbon dioxide measurements as a prognostic indicator of outcome in cardiac arrest. Am J Crit Care 2001;10(6):391-398.

6. Thompson JE, Jaffe MB. Capnographic waveforms in the mechanically ventilated patient. Respir Care 2005;50(1):100-108; discussion 108-109.

7. Moreira MM, Terzi RG, Cortellazzi L, Falcão AL, Moreno H Jr, Martins LC, Coelho OR. Volumetric capnography: in the diagnostic work-up of chronic thromboembolic disease. Vasc Health Risk Manag 2010;6:317-319.

8. Moreira MM, Terzi RG, Paschoal IA, Martins LC, Oliveira EP, Falcão AL. [Thrombolysis in massive pulmonary embolism based on the volumetric capnography]. Arq Bras Cardiol 2010;95(4):e97-e99. Article in multiple languages.

9. Veronez L, Pereira MC, da Silva SM, Barcaui LA, De Capitani EM, Moreira MM, Paschoal IA. Volumetric capnography for the evaluation of chronic airways diseases. Int J Chron Obstruct Pulmon Dis 2014;9:983-989.

10. Ribeiro MA, Silva MT, Ribeiro JD, Moreira MM, Almeida CC, Almeida-Junior AA, et al. Volumetric capnography as a tool to detect early peripheric lung obstruction in cystic fibrosis patients. J Pediatr (Rio J) 2012;88(6):509-517.

11. Almeida CC, Almeida-Júnior AA, Ribeiro MA, Nolasco-Silva MT, Ribeiro JD. Volumetric capnography to detect ventilation inhomogeneity in children and adolescents with controlled persistent asthma. J Pediatr (Rio J) 2011;87(2):163-168.

12. Verschuren F, Heinonen E, Clause D, Roeseler J, Thys F, Meert P, et al. Volumetric capnography as a bedside monitoring of thrombolysis in major pulmonary embolism. Intensive Care Med 2004;30(11): 2129-2132.

13. Hardman JG, Aitkenhead AR. Estimating alveolar dead space from the arterial to end-tidal $\mathrm{CO}_{2}$ gradient: a modeling analysis. Anesth Analg 2003;97(6):1846-1851.

14. Veronez L, Moreira MM, Soares ST, Pereira MC, Ribeiro MA, Ribeiro JD, et al. Volumetric capnography for the evaluation of pulmonary disease in adult patients with cystic fibrosis and noncystic fibrosis bronchiectasis. Lung 2010;188(3):263-268.

15. Kallet RH, Jasmer RM, Pittet JF. Alveolar dead-space response to activated protein $\mathrm{C}$ in acute respiratory distress syndrome. Respir Care 2010;55(5):617-622.

16. Charron C, Repesse X, Bouferrache K, Bodson L, Castro S, Page B, et al. $\mathrm{P}_{\mathrm{aCO}_{2}}$ and alveolar dead space are more relevant than $\mathrm{P}_{\mathrm{aO}} / \mathrm{F}_{\mathrm{IO}_{2}}$ ratio in monitoring the respiratory response to prone position in ARDS patients: a physiological study. Crit Care 2011;15(4):R175.

17. Fengmei G, Jin C, Songqiao L, Congshan Y, Yi Y. Dead space fraction changes during PEEP titration following lung recruitment in patients with ARDS. Respir Care 2012;57(10):1578-1585.

18. Pereira DJ, Moreira MM, Paschoal IA, Martins LC, Metze K, Moreno Junior $\mathrm{H}$. Near-fatal pulmonary embolism in an experimental model: hemodynamic, gasometric and capnographic variables. Rev Bras Cir Cardiovasc 2011;26(3):462-468.

19. Kerr AA. Dead space ventilation in normal children and children with obstructive airways diease. Thorax 1976;31(1):63-69.

20. Wratney AT, Cheifetz IM. Extubation criteria in infants and children. Respir Care Clin N Am 2006;12(3):469-481.

21. Kallet RH, Zhuo H, Liu KD, Calfee CS, Matthay MA. The association between physiologic dead-space fraction and mortality in subjects with ARDS enrolled in a prospective multi-center clinical trial. Respir Care 2014;59(11):1611-1618.

22. Almeida-Junior AA, da Silva MT, Almeida CC, Ribeiro JD. Relationship between physiologic deadspace/tidal volume ratio and gas exchange in infants with acute bronchiolitis on invasive mechanical ventilation. Pediatr Crit Care Med 2007;8(4):372-377.

23. Arnold JH, Bower LK, Thompson JE. Respiratory deadspace measurements in neonates with congenital diaphragmatic hernia. Crit Care Med 1995;23(2):371-375.

24. Ghamra ZW, Arroliga AC. Volumetric capnography in acute respiratory distress syndrome: is the era of day-to-day monitoring finally here? Respir Care 2005;50(4):457-458.

25. McSwain SD, Hamel DS, Smith PB, Gentile MA, Srinivasan S, Meliones JN, Cheifetz IM. End-tidal and arterial carbon dioxide measurements correlate across all levels of physiologic dead space. Respir Care 2010;55(3):288-293.

26. Bhalla AK, Rubin S, Newth CJ, Ross P, Morzov R, Soto-Campos G, Khemani R. Monitoring dead space in mechanically ventilated children: volumetric capnography versus time-based capnography. Respir Care 2015:60(11):1548-1555. 